\title{
Autotoxicity in Some Ornamentals with the Means to Overcome It
}

\author{
Toshiki Asao ${ }^{1}$, Hiroaki Kitazawa, Kazuyori Ushio, Yukio Sueda, \\ Takuya Ban, and M. Habibur Rahman Pramanik \\ Faculty of Life and Environmental Science, Shimane University, 2059 \\ Kamihonjo, Matsue, Shimane, 690-1102, Japan
}

Additional index words. autotoxicity, hydroponics, ornamentals, root exudates

\begin{abstract}
Autotoxicity in some ornamentals was investigated. The plants were grown by hydroponics with or without the addition of activated charcoal (AC) to the nutrient solution. The AC was used to trap the exuded organics from roots. Among the 37 plants under study, growth of lily, prairie gentian, corn poppy, farewell-to-spring, rocket larkspur, and carnation was drastically reduced in the absence of AC compared with those in the presence of $\mathrm{AC}$ in the nutrient solution. Root exudates of some plants were analyzed and several organic compounds were detected. The strong growth inhibitors such as lactic acid in pot marigold, benzoic and $p$-hydroxybenzoic acid in lily, $o$-hydroxyphenylacetic acid in rocket larkspur, benzoic and $p$-hydroxybenzoic acid in sweet pea, and maleic and benzoic acid in prairie gentian were detected in the root exudates. The reduced growth of prairie gentian after prolonged cultivation in a field might be avoided by amending the soil with $\mathrm{AC}$ at a rate of $60 \mathrm{~kg} \cdot 10 \mathrm{a}^{-1}$.
\end{abstract}

Plants synthesize, store, and exude various kinds of organic compounds in their surroundings as exudates, volatiles, or residues of decomposition (Hale and Orcutt, 1987). Some of the released compounds (allelochemicals) inhibit the growth of the source plants (autotoxicity) or the other species grown in the vicinity of source plants (heterotoxicity). This autotoxicity or heterotoxicity can be treated as allelopathy and the autotoxicity was found to be increased if the plants were cultivated consecutively for years on the same land (Rice, 1984) or grown by hydroponic culture without renewal of nutrient solution (Asao et al., 1998a, 2001). One of the principal causes of this growth inhibition in the successive culture of plants has been attributed to the effect of exuded chemicals from plants (Pramanik et al., 2000). Growth of some vegetables such as asparagus, taro, cucumber, and tomato was inhibited by allelochemicals found in their root exudates (Asao et al., 1998a, 2003, 2004; Shafer and Garrison, 1986; Yang, 1982; Yu and Matsui, 1993a). Inhibition in growth of apple, peach, rice, strawberry, and sugarcane has been documented for the autotoxicity (Kitazawa et al., 2005; Mizutani et al., 1988; Rice, 1984). This autotoxicity in tomato (Yu and Matsui, 1993a) and cucumber (Asao et al., 1998a; Pramanik et al., 2000) has been recovered by addition of activated charcoal (AC) to the nutrient solution, because the added AC adsorbed the phytotoxic root exudates and thus favored plant growth. However, research on autotoxicity in ornamentals is limited. Tukey (1969) showed that when chrysanthemum was grown repeatedly

Received for publication 8 Feb. 2007. Accepted for publication 28 June 2007.

${ }^{1}$ To whom reprint requests should be addressed; e-mail asao@life.shimane-u.ac.jp. in the same place for several years, growth was reduced owing to accumulation of toxic substances in the soil. Kaul (2000) reported on autotoxicity in African marigold, but did not identify the allelochemicals involved. So, in this study, we attempted to investigate autotoxicity, if any, in selected ornamentals along with a possible remedial measure to overcome the growth inhibition from autotoxicity.

\section{Materials and Methods}

Planting materials. Thirty-seven different ornamentals belonging to 16 different families were chosen for this experiment (Table 1).

Plant cultivation with or without activated charcoal. Plant cultivation was carried out according to Pramanik et al. (2000). Seedlings, scions, germinated bulbs, and corms of the plants under study were transplanted to plastic containers $(34 \mathrm{~cm} \times 54$ $\mathrm{cm} \times 20 \mathrm{~cm})$ in the greenhouse of Shimane University. The container was filled with $30 \mathrm{~L}$ of continuously aerated $\left(3.8 \mathrm{~L} \cdot \mathrm{min}^{-1}\right)$ $50 \%$ Enshi nutrient solution with electrical conductivity (EC) of $1.3 \mathrm{dS} \cdot \mathrm{m}^{-1}$ (Table 2; Hori, 1966). Two small air filters, each packed with $100 \mathrm{~g}$ of AC (Type GH2C, 4-8 mesh; Takeda Chemical Industry Co., Osaka, Japan), were immersed into the nutrient solution of the container and were attached to the top of tubes with an air pump. The same aeration system was maintained for the nutrient solution without AC. The AC was used to trap the chemicals exuded from the plants and was replaced by fresh AC at 2-week intervals until the end of the experiment for efficient adsorption of the chemicals. The used AC was either immediately extracted with alkaline methanol or stored at $4{ }^{\circ} \mathrm{C}$ for later extraction. $\mathrm{FeSO}_{4} \cdot 7 \mathrm{H}_{2} \mathrm{O}(0.75 \mathrm{~g})$ was added to each solution container at 2 -d intervals because the AC-absorbed Fe-EDTA and $\mathrm{Fe}^{2+}$ was rapidly oxidized to $\mathrm{Fe}^{3+}$ and less available for plants. During cultivation, the water level of the solution containers was kept constant by regularly adding tap water. Nutrient concentrations $\left(\mathrm{NO}_{3}{ }^{-}, \mathrm{PO}_{4}{ }^{2-}, \mathrm{K}^{+}\right.$, $\mathrm{Ca}^{2+}, \mathrm{Mg}^{2+}$, and $\mathrm{Fe}^{3+}$ ) in the solution were adjusted as close as possible to the initial concentration at 2-week intervals on the basis of chemical analyses with an atomic absorption spectrometer (Shimadzu AA-630, Kyoto, Japan) and ion meter (Horiba D-23, Kyoto, Japan). Twelve plants were planted in each container and three containers were used for each treatment (plants with or without $\mathrm{AC}$ ). The $\mathrm{pH}$ of the nutrient solutions ranged from 5.5 to 6.9 irrespective of whether $\mathrm{AC}$ was added to the containers. At the end of the experiment, plant length, number of leaves per plant, maximum root length, flesh and dry weight of shoot and dry weight of root, and number of flowers per plant were recorded.

Gas chromatography-mass spectroscopy analysis of root exudates adsorbed in activated charcoal. The ACs used to trap the exuded organics were desorbed three times using a mixture of methanol $(100 \mathrm{~mL})$ and $0.4 \mathrm{M}$ aqueous $\mathrm{NaOH}(100 \mathrm{~mL})$. Each batch of AC (200 g) was gently shaken with the mixture for $12 \mathrm{~h}$ at room temperature with an electric shaker. The extracts were combined and filtered. The filtrates were neutralized and concentrated to $25 \mathrm{~mL}$ by a rotary vacuum evaporator at $40{ }^{\circ} \mathrm{C}$. Organic compounds in the concentrate were extracted according to $\mathrm{Yu}$ and Matsui (1993b). The concentrated solution was adjusted to $\mathrm{pH} 2.0$ with $4 \mathrm{M} \mathrm{HCl}$, extracted three times with $35 \mathrm{~mL}$ of refined diethyl ether (DE), and another three times with $35 \mathrm{~mL}$ of ethyl acetate (EA). DE2 and EA2 were the ether and ethyl acetatesoluble fractions at $\mathrm{pH} 2.0$, respectively. The DE2 and EA2 fractions were dried over anhydrous $\mathrm{CaSO}_{4}$ and concentrated to $5 \mathrm{~mL}$ each in a rotary evaporator at $40^{\circ} \mathrm{C}$.

All the fractions (DE2 and EA2) extracted from $\mathrm{AC}$ were analyzed with a gas chromatograph coupled to a mass spectrometer (GCMS; Hitachi M-80B, Tokyo) before or after methylation. Fraction DE2 gave a number of peaks in the gas chromatogram, whereas the EA2 fraction gave only a few detectable peaks. An aliquot of the concentrated DE2 fraction ( 1 or $2 \mathrm{~mL}$ ) was diluted in a $50-\mathrm{mL}$ ether solution, treated with diazomethane, and concentrated in a rotary evaporator before being bubbled with a $\mathrm{N}_{2}$ stream in a water bath at $35{ }^{\circ} \mathrm{C}$. One microliter of the concentrated sample was injected into a GCMS unit coupled with a capillary column (TC-5, 60 m; GL Science, Tokyo). Helium was used as the carrier gas at a pressure of 0.8 $\mathrm{kg} \cdot \mathrm{cm}^{-2}$. The initial column temperature was held at $100{ }^{\circ} \mathrm{C}$ for $2 \mathrm{~min}$ and then raised at $5{ }^{\circ} \mathrm{C} \cdot \mathrm{min}^{-1}$ to a final temperature of $260{ }^{\circ} \mathrm{C}$ with isotherm for $10 \mathrm{~min}$. The injector temperature was held at $270{ }^{\circ} \mathrm{C}$. The ionization voltage and temperature in the electron impact mode were $70 \mathrm{eV}$ and $250{ }^{\circ} \mathrm{C}$, respectively. 
Table 1. Planting materials.

\begin{tabular}{|c|c|c|c|}
\hline Family & Ornamental & Scientific name & Cultivar \\
\hline \multirow[t]{11}{*}{ Compositae } & Pot marigold & Callendula officinalis L. & Gold-star \\
\hline & Cornflower & Centaurea cyanus L. & Echo-sultan \\
\hline & Chrysanthemum & Chrysanthemum morifolium Ramat. & Shuhou-no-chikara \\
\hline & Cosmos & Cosmos bipinnatus Cav. & Dearboro \\
\hline & Zinnia & Zinnia elegans Jacq. & Sunbow-orange \\
\hline & Thistle & Cirsium japanicum DC. & Rakuonzi-Azami \\
\hline & Sunflower & Helianthus annuns L. & Big-smile \\
\hline & Safflower & Carthamus tinctorius L. & $-^{z}$ \\
\hline & African marigold & Tagetes erecta $\mathrm{L}$. & Orange-isis \\
\hline & China aster & Callistephus chinensis Nees & Kurenai \\
\hline & Coneflower & Rudbeckia hirta L. & Gloriosa-daisy \\
\hline \multirow[t]{4}{*}{ Liliaceae } & Tulip & Tulipa gesneriana L. & Blue-champion \\
\hline & Thunberg lily & Lilium $\times$ elegans Thunb. & Iberu-flora \\
\hline & Toritelia & Tritelelia laxa Benth & Bridgesii \\
\hline & Lily & Lilium $\times$ formolongi Hort. & Hananomai \\
\hline \multirow[t]{4}{*}{ Labiatae } & Rocket larkspur & Delphinium ajacis L. & Lilac \\
\hline & Love-in-a-mist & Nigella damascena $\mathrm{L}$. & Transformer \\
\hline & Scarlet sage & Salvia splendens Ker. & Lavender \\
\hline & Fan columbine & Aquilegia flabellate Sieb. et Zucc. & Macana-giant \\
\hline \multirow[t]{3}{*}{ Caryophyllaceae } & Corn cockl & Agrostemma githago L. & Purple queen \\
\hline & Gypsophilla & Gypsophila elegans M.B & Covent-garden \\
\hline & Carnation & Dianthus caryophyllus L. & Feminist \\
\hline \multirow[t]{2}{*}{ Leguminosae } & Sweet pea & Lathyrus odoratus L. & Rolay-lavender \\
\hline & Lupine & Lupine luteus L. & Lassell \\
\hline \multirow[t]{2}{*}{ Cruciferae } & Rape blossoms & Brassica rapa $\mathrm{L}$. & Wase-fushimi-kanzaki \\
\hline & Stock & Matthiola incana $\mathrm{R}$. Br. & Love-me rose \\
\hline Onagraceae & Farewell-to-spring & Godetia amoena $\mathrm{G}$. Don & Kyokuhai \\
\hline Umbelliferae & Bishop's weed & Ammi majus L. & $-^{\mathrm{z}}$ \\
\hline Scrophulariaceae & Snapdragon & Antirrhinum majus L. & F1-butterfly-bronze \\
\hline Papaveraceae & Corn poppy & Papaver rhoeas L. & Red-sales \\
\hline Amaryllidaceae & Narcissus & Narcissus tazetta L. & Fernandesii \\
\hline \multirow[t]{2}{*}{ Amaranthaceae } & Feather cockscomb & Celosia argentea L. & Red-cupid \\
\hline & Globe amaranth & Gomphrena globosa L. & Strawberryfields \\
\hline Gentianaceae & Prairie gentian & Eustoma grandiflorum (Raf.) Shinn. & Blue line 1 \\
\hline Campanulaceae & Balloon flower & Platycodon grandiflorum A. DC. & Samidare-murasaki \\
\hline Plumbaginaceae & Statice & Limonium sinuatum Mill. & Marine-blue \\
\hline Solanaceae & Chinese-lantern plant & Physalis alkekengi L. var. franchetii & Tanba houzuki. \\
\hline
\end{tabular}

'Unknown.

Table 2. Enshi nutrient solution. ${ }^{\mathrm{z}}$

\begin{tabular}{lc}
\hline Chemicals & Amounts $^{\mathrm{y}}(\mathrm{g} / 1000 \mathrm{~L})$ \\
\hline $\mathrm{Ca}\left(\mathrm{NO}_{3}\right)_{2} \cdot 4 \mathrm{H}_{2} \mathrm{O}$ & 950 \\
$\mathrm{KNO}_{3}$ & 810 \\
$\mathrm{MgSO}_{4} \cdot 7 \mathrm{H}_{2} \mathrm{O}$ & 500 \\
$\mathrm{NH}_{4} \mathrm{H}_{2} \mathrm{PO}_{4}$ & 155 \\
$\mathrm{H}_{3} \mathrm{BO}_{3}$ & 3 \\
$\mathrm{ZnSO}_{4} \cdot 7 \mathrm{H}_{2} \mathrm{O}$ & 0.22 \\
$\mathrm{MnSO}_{4} \cdot 4 \mathrm{H}_{2} \mathrm{O}$ & 2 \\
$\mathrm{CuSO}_{4} \cdot 5 \mathrm{H}_{2} \mathrm{O}$ & 0.05 \\
$\mathrm{Na}_{2} \mathrm{MoO}_{4} \cdot 2 \mathrm{H}_{2} \mathrm{O}$ & 0.02 \\
\hline
\end{tabular}

zFull strength.

${ }^{y}$ Amounts of salts per $1000 \mathrm{~L}$ of tap water (Hori, 1966).

Bioassay with identified chemicals. The bioassay was carried out according to Asao et al. (1998b). Aqueous solutions of the identified compounds at concentrations of 0 (control), 50, 100, 200, and $400 \mu \mathrm{M}$ were prepared with a $50 \%$ Enshi nutrient solution (EC $1.3 \mathrm{dS} \cdot \mathrm{m}^{-1}$ ). The test solutions were added to flasks (capacity $\approx 420 \mathrm{~mL}$ ) wrapped with black polyethylene to avoid direct light to the roots. Some selected test plants were transplanted to each flask with urethane foam as support. The planted flasks were placed in a growth chamber at $25^{\circ} \mathrm{C}$ with a light intensity of 74 to $81 \mu \mathrm{mol} \cdot \mathrm{s}^{-1} \mu \mathrm{m}^{-2}$ and a $16-\mathrm{h}$ photoperiod. To minimize the effect of aeration and the microbial degradation of organic compounds (Sundin and Waechter-
Kristensen, 1994) on the bioassay, we renewed the test solutions in the planted flask every 3- or 4-d interval. The plants were grown for 2 weeks and then the fresh and dry weights of shoots were measured. Each treatment was replicated 10 times.

Bioassay in soils amended with activated charcoal. Some soil was collected from a field successively cultivated with prairie gentian for over 10 years in Nagano prefecture, Japan, and was used as medium of growth for the bioassay. Three kilograms of the soil was pulverized and placed in each plastic container $(17 \mathrm{~cm} \times 29 \mathrm{~cm} \times 9.5 \mathrm{~cm})$ after amending with $\mathrm{AC}$ corresponding to the rate of 0 (control), 30, 60, 120, 240, and 480 $\mathrm{kg} \cdot 10 \mathrm{a}^{-1}$. Soil collected outside the prairie gentian field was also used as a reference to compare the growth performance of the test plants growth with or without AC (control). The physical and chemical properties of the reference soil were essentially similar to the soil in the prairie gentian field (data not shown). Ten prairie gentian seedlings were planted into the treated containers and were placed in the Shimane University greenhouse. Irrigation $(500 \mathrm{~mL}$ water $)$ was applied to each container at 2-week intervals and 500 $\mathrm{mL}$ Enshi nutrient solution (50\%) with EC of $1.3 \mathrm{dS} \cdot \mathrm{m}^{-1}$ was applied to each container at 2 -week intervals. The cultivation was continued for 8 weeks.
At the end of the experiment plant length, number of leaves per plant, maximum root length, shoot dry weight and root dry weight, and number of flowers per plant were recorded.

\section{Results and Discussion}

Thirty-seven ornamentals were grown through hydroponic culture with or without addition of AC in the nutrient solution. Plant growth was significantly affected by the added AC. Performances of the plants were evaluated as percent comparing the growth of the plants grown without AC (control) with those grown with AC. Different plants responded differently to the addition of $\mathrm{AC}$ (Table 3). Growth in lily was the most severely retarded. Plant length, number of leaves and flowers per plant, root length, and plant dry weight almost all declined significantly in most of the plants grown without AC compared with those grown with AC. However, root growth was found to be more responsive to AC than the other studied parameters possibly for being the roots in direct contract with the exuded chemicals (Pramanik et al., 2000). Root dry weight of lily and rocket larkspur was reduced to $\approx 85 \%$ and $74 \%$, respectively, followed by prairie gentian with growth reduced to $55 \%$. Root length of lily was reduced to $\approx 58 \%$, whereas that in prairie-gentian was reduced to $\approx 49 \%$. It appears that lily, prairie gentian, corn poppy, pot marigold, toritelia, and farewellto-spring were the most sensitive to autotoxicity. Autotoxicity in plants from their own exuded chemicals is also observed in natural ecosystems (Rice, 1984) and was well documented in many crops (Asao et al., 1998a; Kitazawa et al., 2005; Mizutani et al., 1988; Pramanik et al., 2000; Yu and Matsui, 1993a). Asao et al. (2001) detected autotoxicity in some species of Umbellifeae, Compositiae, and Cruciferae. So, autotoxicity in the ornamentals might be incited by the exuded chemicals from their roots. Stimulated growth was observed in the plants such as African marigold, love-in-a-mist, and rape blossoms grown in nonrenewal nutrient solution, however. The exact reasons for this growth stimulation in the latter plants were not discovered. However, it is well known that a chemical at low concentration acts as a growth stimulant to a plant and the same chemical at high concentration becomes toxic or growth-retardant to the same plant (Rizvi and Rizvi, 1992). Functional activity of an allelochemical depends on its concentration and time exposure to the test plants. So, it is possible that the quality and quantity of root exudates in the nutrient solution in absence of AC might not be sufficient to inhibit growth in the latter ornamental plants, but rather their growth was stimulated.

Root exudates from the ornamentals were analyzed and some compounds were detected. The identified chemicals were mainly some small chain aliphatic acids and some simple phenolic acids or phenolic compounds and those varied from extract to extract in the 
ornamentals that experienced autotoxicity. Eleven organic compounds were detected in the root exudates of toritelia roots and seven in prairie gentian (Table 4). Many compounds in the root exudates of the plants are yet to be identified. However, at least one aliphatic acid or phenolic compound has been detected in the root exudates of the studied plants. A bioassay was carried out to evaluate the inhibition potential of some identified compounds. Different test concentrations were made with the compounds and a bioassay was furnished with some test plants. Almost all the compounds inhibited the growth of tested plants in a concentrationdependent manner. Lactic acid significantly reduced fresh shoot weight (FSW) and root dry weight (RDW) in pot marigold to $79 \%$ and $66 \%$ of control, respectively, even at low concentration $(50 \mu \mathrm{M})$ (Table 5). Benzoic and $p$-hydroxybenzoic acid in lily, even at 50

Table 3. Growth performances of some ornamental plants grown through hydroponic culture in the presence or absence of activated charcoal (AC) in the nutrient solution $(\%)^{\mathrm{z}}$

\begin{tabular}{|c|c|c|c|c|c|c|c|c|}
\hline Family & Ornamental & Plant length & $\begin{array}{l}\text { No. of } \\
\text { leaves }\end{array}$ & $\begin{array}{l}\text { Maximum } \\
\text { root length }\end{array}$ & $\begin{array}{l}\text { Flesh wt } \\
\text { of shoot }\end{array}$ & $\begin{array}{l}\text { Dry wt } \\
\text { of shoot }\end{array}$ & $\begin{array}{l}\text { Dry wt } \\
\text { of root }\end{array}$ & $\begin{array}{c}\text { No. of flowersper } \\
\text { plant }\end{array}$ \\
\hline \multirow[t]{11}{*}{ Compositae } & Pot marigold & $89.9^{* y}$ & $95.8^{\mathrm{NS}}$ & $101.9^{\mathrm{NS}}$ & $55.9^{* *}$ & $79.9^{*}$ & $70.4^{* *}$ & - \\
\hline & Cornflower & $102.9^{\mathrm{NS}}$ & $115.5^{* *}$ & $102.1^{\mathrm{NS}}$ & - & $111.3^{\mathrm{NS}}$ & $86.8^{\mathrm{NS}}$ & - \\
\hline & Chrysanthemum & $103.8^{\mathrm{NS}}$ & - & - & $99.9^{\mathrm{NS}}$ & $98.9^{\mathrm{NS}}$ & $126.6 * *$ & - \\
\hline & Cosmos & $-^{x}$ & - & - & $119.9^{\mathrm{NS}}$ & $120.1^{\mathrm{NS}}$ & $111.2^{\mathrm{NS}}$ & - \\
\hline & Zinnia & $93.7^{\mathrm{NS}}$ & - & - & $88.6^{\mathrm{NS}}$ & $91.7^{\mathrm{NS}}$ & $96.8^{\mathrm{NS}}$ & - \\
\hline & Thistle & $114.8^{\mathrm{NS}}$ & - & $114.6^{*}$ & $99.9^{\mathrm{NS}}$ & $118.1^{\mathrm{NS}}$ & $120.8^{\mathrm{NS}}$ & $142.9^{\mathrm{NS}}$ \\
\hline & Sunflower & $106.1^{\mathrm{NS}}$ & $96.8^{\mathrm{NS}}$ & $84.4^{\mathrm{NS}}$ & $113.3^{\mathrm{NS}}$ & - & $95.8^{\mathrm{NS}}$ & $100.0^{\mathrm{NS}}$ \\
\hline & Safflower & $104.8^{\mathrm{NS}}$ & $89.7 * *$ & $79.4 * *$ & $91.6^{\mathrm{NS}}$ & $100.2^{\mathrm{NS}}$ & $84.6^{\mathrm{NS}}$ & $100.0^{\mathrm{NS}}$ \\
\hline & African marigold & $146.1 * *$ & $95.5^{\mathrm{NS}}$ & - & $146.7 * *$ & $176.2 * *$ & - & $100.0^{\mathrm{NS}}$ \\
\hline & China aster & $103.2^{\mathrm{NS}}$ & $97.3^{\mathrm{NS}}$ & $79.1 * *$ & $80.7^{*}$ & $82.4^{*}$ & $70.6^{* *}$ & $68.4^{*}$ \\
\hline & Coneflower & $93.7^{\mathrm{NS}}$ & $87.2^{\mathrm{NS}}$ & $102.8^{\mathrm{NS}}$ & $79.2 *$ & $84.2 *$ & $119.4^{\mathrm{NS}}$ & $80.3^{\mathrm{NS}}$ \\
\hline \multirow[t]{4}{*}{ Liliaceae } & Tulip & $110.6^{\mathrm{NS}}$ & $102.6^{\mathrm{NS}}$ & $86.2^{\mathrm{NS}}$ & $104.4^{\mathrm{NS}}$ & $110.5^{\mathrm{NS}}$ & $69.7^{\mathrm{NS}}$ & $100.0^{\mathrm{NS}}$ \\
\hline & Thunberg lily & $88.2 *$ & $96.0^{\mathrm{NS}}$ & $118.2^{\mathrm{NS}}$ & $107.3^{\mathrm{NS}}$ & $97.1^{\mathrm{NS}}$ & $155.3^{\mathrm{NS}}$ & - \\
\hline & Toritelia & $93.1 *$ & $100.0^{\mathrm{NS}}$ & $55.9 * *$ & $77.2 * *$ & $80.2 * *$ & $74.8 * *$ & $71.5 * *$ \\
\hline & Lily & $37.2 * *$ & $64.6 * *$ & $42.1 * *$ & $13.5^{* *}$ & $13.2 * *$ & $15.6 * *$ & - \\
\hline \multirow[t]{4}{*}{ Labiatae } & Rocket larkspur & $71.5^{* *}$ & $93.8^{\mathrm{NS}}$ & $51.4 * *$ & $25.5 * *$ & $38.1 * *$ & $26.3 * *$ & $88.3^{\mathrm{NS}}$ \\
\hline & Love-in-a-mist & $181.4 * *$ & $110.3^{\mathrm{NS}}$ & $122.7^{\mathrm{NS}}$ & $151.6 * *$ & $127.1 *$ & $162.5 * *$ & $100.0^{\mathrm{NS}}$ \\
\hline & Scarlet sage & $99.5^{\mathrm{NS}}$ & $101.0^{\mathrm{NS}}$ & $91.6^{\mathrm{NS}}$ & $103.6^{\mathrm{NS}}$ & $106.1^{\mathrm{NS}}$ & $112.5^{\mathrm{NS}}$ & - \\
\hline & Fan columbine & $104.4^{\mathrm{NS}}$ & - & $68.1 * *$ & $74.6^{*}$ & $74.2 *$ & $80.3^{\mathrm{NS}}$ & - \\
\hline \multirow[t]{3}{*}{ Caryophyllaceae } & Corn cockl & $74.1 * *$ & $85.4 * *$ & $62.1 * *$ & $27.9 * *$ & $33.1 * *$ & $83.7^{\mathrm{NS}}$ & - \\
\hline & Gypsophilla & $105.3^{\mathrm{NS}}$ & $102.6^{\mathrm{NS}}$ & $83.9 * *$ & $99.9^{\mathrm{NS}}$ & $118.1^{\mathrm{NS}}$ & $121.8^{\mathrm{NS}}$ & $100.0^{\mathrm{NS}}$ \\
\hline & Carnation & $42.4 * *$ & $75.0 * *$ & $61.2 * *$ & $34.6 * *$ & $46.5^{* *}$ & $58.5 * *$ & - \\
\hline \multirow[t]{2}{*}{ Leguminosae } & Sweet pea & $85.1 *$ & $105.8^{\mathrm{NS}}$ & - & $78.5^{*}$ & $82.2 *$ & $79.8^{\mathrm{NS}}$ & - \\
\hline & Lupine & $98.1^{\mathrm{NS}}$ & $106.5^{\mathrm{NS}}$ & - & $120.3^{\mathrm{NS}}$ & $107.2^{\mathrm{NS}}$ & $96.3^{\mathrm{NS}}$ & $71.9^{\mathrm{NS}}$ \\
\hline \multirow[t]{2}{*}{ Cruciferae } & Rape blossoms & $106.1 *$ & $100.0^{\mathrm{NS}}$ & $95.6^{\mathrm{NS}}$ & $121.2 * *$ & $113.3^{*}$ & $50.2 *$ & - \\
\hline & Stock & $60.3 *$ & $89.9^{\mathrm{NS}}$ & $101.5^{\mathrm{NS}}$ & $62.9 * *$ & $78.3 * *$ & $100.0^{\mathrm{NS}}$ & $95.3^{\mathrm{NS}}$ \\
\hline Onagraceae & Farewell-to-spring & $78.4 * *$ & $92.1 *$ & $75.1 * *$ & $44.7 * *$ & $51.4 * *$ & $28.3 * *$ & $56.3 * *$ \\
\hline Umbelliferae & Bishop's weed & $91.3 *$ & $97.5^{\mathrm{NS}}$ & - & $66.3 * *$ & $69.4 *$ & - & $91.1^{\mathrm{NS}}$ \\
\hline Scrophulariaceae & Snapdragon & $72.8 * *$ & $96.7^{\mathrm{NS}}$ & $100.7^{\mathrm{NS}}$ & $46.1 * *$ & $56.3 * *$ & $79.5^{\mathrm{NS}}$ & $73.1^{*}$ \\
\hline Papaveraceae & Corn poppy & $50.4^{*}$ & $75.3^{\mathrm{NS}}$ & $98.1^{\mathrm{NS}}$ & $32.1 * *$ & $52.5^{*}$ & $52.6^{*}$ & - \\
\hline Amaryllidaceae & Narcissus & $97.1^{\mathrm{NS}}$ & $102.0^{\mathrm{NS}}$ & $78.8^{* *}$ & $96.3^{\mathrm{NS}}$ & $89.2^{\mathrm{NS}}$ & $97.7^{\mathrm{NS}}$ & $100.0^{\mathrm{NS}}$ \\
\hline \multirow[t]{2}{*}{ Amaranthaceae } & Feather cockscomb & $92.9^{\mathrm{NS}}$ & $80.7 *$ & $85.7^{\mathrm{NS}}$ & $100.5^{\mathrm{NS}}$ & - & - & $100.0^{\mathrm{NS}}$ \\
\hline & Globe amaranth & $102.8^{\mathrm{NS}}$ & $100.0^{\mathrm{NS}}$ & $102.8^{\mathrm{NS}}$ & $84.5 * *$ & $83.2 * *$ & $100.0^{\mathrm{NS}}$ & $82.7 * *$ \\
\hline Gentianaceae & Prairie gentian & $83.8 * *$ & $107.9^{*}$ & $51.1 * *$ & $50.8 * *$ & $60.2 * *$ & $45.4 * *$ & $62.2 * *$ \\
\hline Campanulaceae & Balloon flower & $117.5^{*}$ & $102.5^{\mathrm{NS}}$ & $78.8 * *$ & $95.7^{\mathrm{NS}}$ & $89.4^{\mathrm{NS}}$ & $112.5^{\mathrm{NS}}$ & $113.2^{\mathrm{NS}}$ \\
\hline Plumbaginaceae & Statice & $109.2^{\mathrm{NS}}$ & $94.2^{\mathrm{NS}}$ & $98.1^{\mathrm{NS}}$ & $94.7^{\mathrm{NS}}$ & $97.8^{\mathrm{NS}}$ & $68.5^{*}$ & $114.2^{\mathrm{NS}}$ \\
\hline Solanaceae & Chinese-lantern plant & $105.3^{\mathrm{NS}}$ & $104.7^{\mathrm{NS}}$ & - & $67.6 * *$ & $64.8 * *$ & $74.8 * *$ & $114.7^{\mathrm{NS}}$ \\
\hline
\end{tabular}

${ }^{\mathrm{z}}$ Growth performance $(\%)=$ growth in absence of AC/growth in presence of $\mathrm{AC} \times 100$.

${ }^{y}$ Significant at $5 \%$ level $(*), 1 \%$ level $(* *)$ and not significant $\left({ }^{\mathrm{NS}}\right)$ by $t$ test $(\mathrm{n}=36)$.

${ }^{\mathrm{x}}$ No data.

Table 4. The compounds identified in the exudates of some ornamentals adsorbed on activated charcoal added in the nutrient solution.

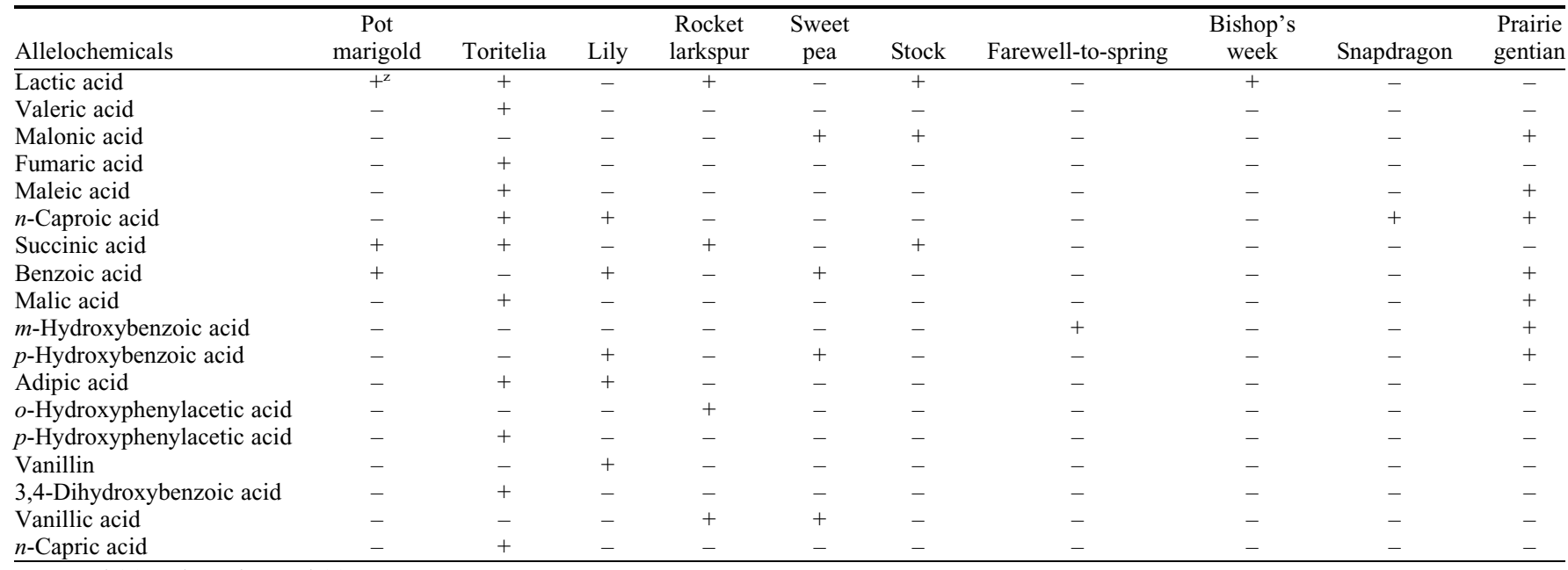

${ }^{\mathrm{z}}$ Detected $(+)$ and not detected $(-)$. 


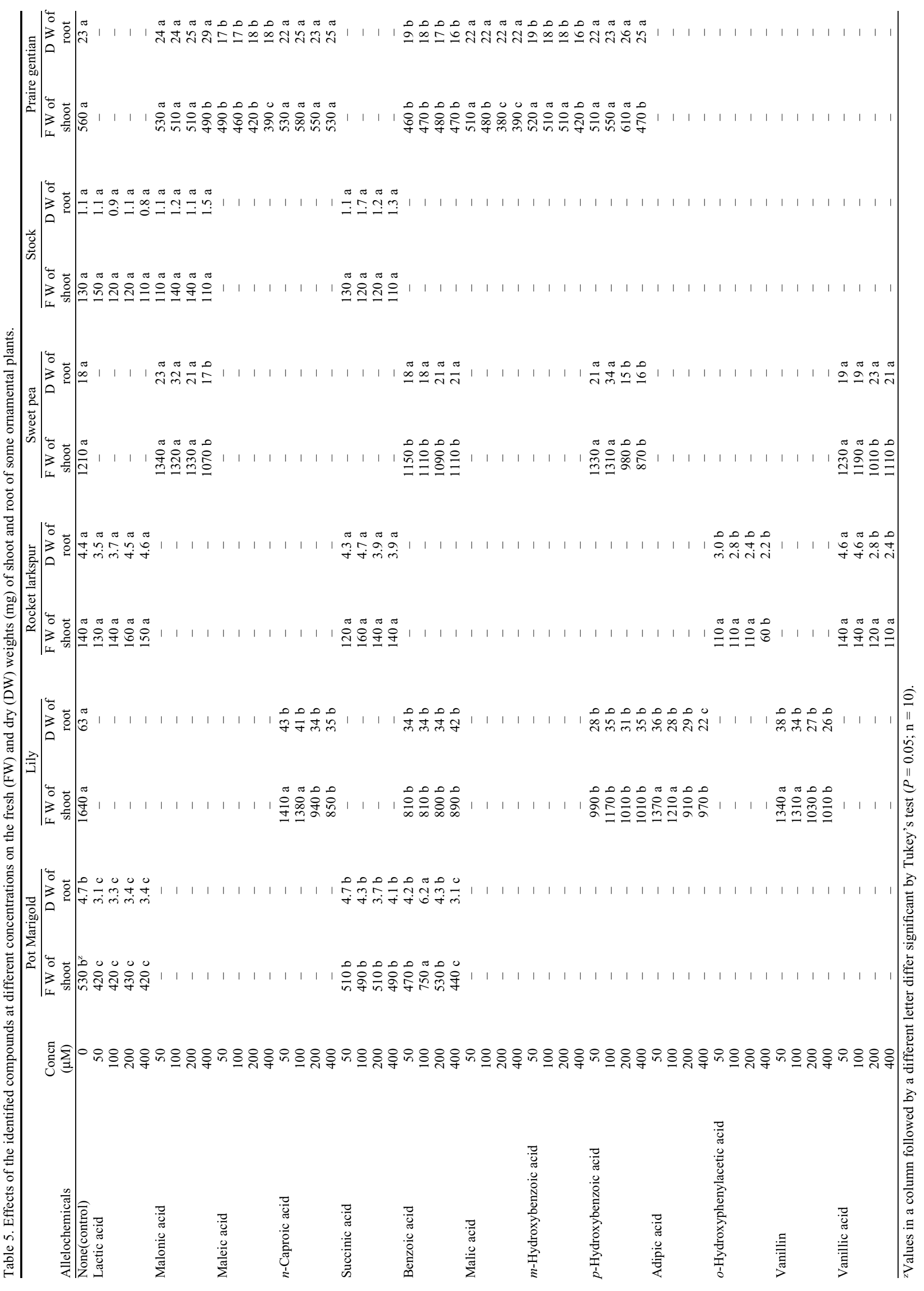

HortScience Vol. 42(6) October 2007 
Table 6. Effects of activated charcoal (AC) on the growth of prairie gentian, an ornamental plant, grown on the soil of prairie gentian field amended with different amount of the AC.

\begin{tabular}{lccccccc}
\hline & $\begin{array}{c}\text { Addition } \\
\text { of AC } \\
(\mathrm{kg} / 10 \mathrm{a})\end{array}$ & $\begin{array}{c}\text { Plant } \\
\text { length } \\
(\mathrm{cm})\end{array}$ & $\begin{array}{c}\text { No. of } \\
\text { leaves }\end{array}$ & $\begin{array}{c}\text { Dry wt } \\
\text { of shoot }(\mathrm{g})\end{array}$ & $\begin{array}{c}\text { Maximum root } \\
\text { length }(\mathrm{cm})\end{array}$ & $\begin{array}{c}\text { Dry wt } \\
\text { of root }(\mathrm{g})\end{array}$ & $\begin{array}{c}\text { No. of flowers } \\
\text { per plant }\end{array}$ \\
\hline Noil & - & $50.6 \mathrm{a}^{\mathrm{z}}$ & $11.4 \mathrm{~b}$ & $2.06 \mathrm{a}$ & $19.2 \mathrm{a}$ & $0.18 \mathrm{~b}$ & $6.7 \mathrm{a}$ \\
Successive & - & $39.9 \mathrm{c}$ & $11.1 \mathrm{bc}$ & $1.29 \mathrm{c}$ & $15.6 \mathrm{~b}$ & $0.25 \mathrm{a}$ & $5.6 \mathrm{~b}$ \\
Successive & 30 & $40.8 \mathrm{c}$ & $11.7 \mathrm{~b}$ & $1.31 \mathrm{c}$ & $14.6 \mathrm{bc}$ & $0.18 \mathrm{~b}$ & $5.2 \mathrm{c}$ \\
Successive & 60 & $48.4 \mathrm{a}$ & $12.2 \mathrm{a}$ & $1.85 \mathrm{a}$ & $18.1 \mathrm{a}$ & $0.19 \mathrm{~b}$ & $6.8 \mathrm{a}$ \\
Successive & 120 & $44.0 \mathrm{~b}$ & $11.4 \mathrm{~b}$ & $1.60 \mathrm{~b}$ & $16.5 \mathrm{~b}$ & $0.19 \mathrm{~b}$ & $6.7 \mathrm{a}$ \\
Successive & 240 & $42.2 \mathrm{bc}$ & $11.2 \mathrm{bc}$ & $1.54 \mathrm{~b}$ & $14.5 \mathrm{bc}$ & $0.20 \mathrm{ab}$ & $5.8 \mathrm{~b}$ \\
Successive & 480 & $40.3 \mathrm{c}$ & $10.9 \mathrm{c}$ & $1.35 \mathrm{c}$ & $10.1 \mathrm{c}$ & $0.11 \mathrm{c}$ & $5.4 \mathrm{c}$ \\
\hline
\end{tabular}

${ }^{2}$ Values in a column followed by a different letter differ significant by Tukey's test $(P=0.05 ; \mathrm{n}=10)$.

$\mu \mathrm{M}$, significantly reduced FSW to $49 \%$ and $60 \%$ of over control, $n$-caproic, benzoic, $p$ hydroxybenzoic, and adipic acid and vanillin decreased RDW to $68 \%, 54 \%, 44 \%, 57 \%$, and $60 \%$ of control, respectively. $o$-Hydroxyphenylacetic acid at $50 \mu \mathrm{m}$ reduced RDW in rocket larkspur to $68 \%$ of control (Table 5). Quantity and quality of exuded allelochemicals varied from plants to plants (Inderjit, 1996) and in cucumber plants, root exudation rate of different chemicals was found to range from 0.20 to $4.17 \mu \mathrm{g} / \mathrm{d}$ per plant (Pramanik et al., 2000). This low concentration is apparently not enough to cause autotoxicity in cucumber plants, but those cucumber plants experienced autotoxicity when grown in absence of $\mathrm{AC}$ in the nutrient solution plant (Pramanik et al., 2000). Actually, in natural conditions, occurrence of a chemical at high concentrations (100 $\mu \mathrm{M}$ or more) is rare or absent. However, under field conditions or hydroponic culture, the exuded compounds affect plant growth by additive or synergistic means (Inderjit, 1996) and thus, the compounds even at low concentrations could induce significant growth inhibition in plants, although their threshold inhibition at the individual level is quite high (Rice, 1984). Identical results were found in the experiment (Table 5). So, it appears that the identified compounds would be toxic enough to affect growth of the ornamental plants by additive or synergistic effects.

Performances of prairie gentian were very poor when successively grown for years in the same land. Significant growth inhibition was noticed in the plants grown in soils from a prairie gentian field without AC compared with those grown in reference soil (soil from outside the russell prairie gentian field) (Table 6 ). It suggests that soil from a prairie gentian field has some growth inhibitors. In hydroponic culture, we also detected some growth inhibitors in the root exudates of the test plant (Tables 4 and 5). Those inhibitors should have been adsorbed when the soil was amended with AC. Thus, the growth of the test plants was increased with an increase in amount of AC from 30 to $60 \mathrm{~kg} \cdot 10 \mathrm{a}^{-1}$ followed by a gradual decline at the highest dose of AC (480 $\left.\mathrm{kg} \cdot 10 \mathrm{a}^{-1}\right)$. This high dose of AC might have affected other chemical properties in soil. Results revealed that the test plant length was increased by $96 \%$ over control as a result of the addition of AC $\left(60 \mathrm{~kg} \cdot 10 \mathrm{a}^{-1}\right)$. Shoot dry weight and root length were increased by $90 \%$ and $94 \%$, respectively, over control for the same concentration $\left(60 \mathrm{~kg} \cdot 10 \mathrm{a}^{-1}\right)$. Flower setting was also increased at $60 \mathrm{~kg}$ AC per 10a. This indicated that the reduced growth of prairie gentian after prolonged cultivation in a field could be corrected by amending the soil with $\mathrm{AC}$ at the rate of $60 \mathrm{~kg} \cdot 10 \mathrm{a}^{-1}$.

In conclusion, of the ornamentals experiencing autotoxicity owing to the chemicals exuded from their roots being more specific, this autotoxicity could be reduced, at least to some extent, using $\mathrm{AC}$ in the root media.

\section{Literature Cited}

Asao, T., K. Hasegawa, Y. Sueda, K. Tomita, K. Taniguchi, T. Hosoki, M.H.R. Pramanik, and Y. Matsui. 2003. Autotoxicity of root exudates from taro. Scientia Hort. 97:389-396.

Asao, T., H. Kitazawa, T. Ban, and M.H.R. Pramanik. 2004. Search of autotoxic substances in some leaf vegetables. J. Jpn. Soc. Hort. Sci. 73:247-249. (in Japanese with English summary)

Asao, T., M. Umeyama, K. Ohta, T. Hosoki, N. Ito, and H. Ueda. 1998a. Decrease of yield of cucumber by non-renewal of the nutrient hydroponic solution and its reversal by supplementation of activated charcoal. J. Jpn. Soc. Hort. Sci. 67:99-105. (in Japanese with English summary).

Asao, T., N. Ohtani, N. Shimizu, M. Umeyama, K. Ohta, and T. Hosoki. 1998b. Possible selection of cucumber cultivars suitable for a closed hydroponics system by the biossay with cucumber seedlings. Soc. High Tech. Agr. 10:92-95. (in Japanese with English summary).

Asao, T., K. Taniguchi, K. Tomita, and T. Hosoki. 2001. Species differences in the susceptibility to autotoxicity among leaf vegetable grown in hydroponics. J. Jpn. Soc. Hort. Sci. 70:519521. (in Japanese with English summary).

Hale, M.G. and D.M. Orcutt. 1987. Allelochemical stress, p. 117-127. In: M.G. Hale and D.M. Orcutt (eds.). The physiology of plants under stress. John Wiley \& Sons, New York.

Hori, H. 1966. Gravel culture of vegetables and ornamentals. 3rd ed. Nutrient Solution, Yokendo, Tokyo, Japan. p. 60-79 (in Japanese).

Inderjit, 1996. Plant phenolics in allelopathy. Bot. Rev. 62:186-202.

Kaul, K. 2000. Autotoxicity in Tagets erecta L. on its own germination and seedling growth. Allelopathy J. 7:109-113.

Kitazawa, H., T. Asao, T. Ban, M.H.R. Pramanik, and T. Hosoki. 2005. Autotoxicity of root exudates from strawberry. J. Hort. Sci. Biot. 80: 677-680.

Mizutani, F., R. Hirota, and K. Kadoya. 1988. Growth inhibiting substances from peach roots and their possible involvement in peach replant problems. Acta Hort. 233:37-43.

Pramanik, M.H.R., M. Nagai, T. Asao, and Y. Matsui. 2000. Effects of temperature and photoperiod on the phytotoxic root exudates of cucumber (Cucumis sativus) in hydroponic culture. J. Chem. Ecol. 28:1953-1967.

Rice, E.L. 1984. Allelopathy. Academic Press, Orlando, FL.

Rizvi, S.J.H. and V. Rizvi. 1992. Allelopathy. Basic and applied aspects. Chapman \& Hall, New York.

Shafer, W.E. and S.A. Garrison. 1986. Allelopathic effects of soil incorporated asparagus roots on lettuce, tomato, and asparagus seedling emergence. HortScience 21:82-84.

Sundin, P. and B. Waechter-Kristensen. 1994. Degradation of phenolic acids by bacteria from liquid hydroponic culture of tomato, p. 473475. In: P.C. Struik, W.J. Vredenberg, J.A Renkema and J.E. Parlevliet. Plant production on the threshold of a new century. Kluwer Academic Publishers, Dordrecht, The Netherlands.

Tukey, H.B., Jr. 1969. Implications of allelopathy in agricultural plant science. Bot. Rev. 35:1-16.

Yang, H.-J. 1982. Autotoxicity of Asparagus officinalis L. J. Amer. Soc. Hort. Sci. 107:860-862.

Yu, J.Q. and Y. Matsui. 1993a. Effect of addition of activated charcoal to the nutrient solution on the growth of tomato grown in the hydroponic culture. Soil Sci. Plant Nutr. 39:13-22.

Yu, J.Q. and Y. Matsui. 1993b. Extraction and identification of the phytotoxic substances accumulated in the nutrient solution for the hydroponic culture of tomato. Soil Sci. Plant Nutr. 39:691-700. 